\section{National Arthritis Awareness Month — May 2017}

May is National Arthritis Awareness Month. In the United States, approximately 54 million (I) adults have some form of doctor-diagnosed arthritis; this number is projected to increase to 78 million by 2040 (2). In addition, arthritis-attributable activity limitation currently affects an estimated 24 million adults with arthritis (1), and this is expected to rise to 35 million by 2040 (2). Approximately one in three adults with arthritis have severe joint pain (1). Arthritis is a leading cause of disability and makes it harder to manage other co-occurring conditions, such as diabetes, heart disease, and obesity. A Vital Signs report on arthritis prevalence (1) was published in MMWR in March 2017 to increase awareness of arthritis, its impact in the United States, and what can be done by health care providers, adults with arthritis, and state and community leaders to address these issues.

CDC recommends physical activity and a variety of evidence-based physical activity and self-management education programs. Physical activity can reduce arthritis pain and improve function by about $40 \%$, and self-management education workshops, such as the Chronic Disease Self-Management Program, have shown $10 \%-20 \%$ improvements in pain, fatigue, and depression in adults with arthritis (3). CDC funds 12 state health departments and several national organizations to disseminate these programs in local communities. Additional information is available at https://www.cdc.gov/ arthritis/interventions/index.htm and https://www.cdc.gov/ arthritis/partners/index.htm.

\section{References}

1. Barbour KE, Helmick CG, Boring M, Brady TJ. Vital signs: prevalence of doctor-diagnosed arthritis and arthritis-attributable activity limitation-United States, 2013-2015. MMWR Morb Mortal Wkly Rep 2017;66:246-53. https://doi.org/10.15585/mmwr.mm6609e1

2. Hootman JM, Helmick CG, Barbour KE, Theis KA, Boring MA. Updated projected prevalence of self-reported doctor-diagnosed arthritis and arthritis-attributable activity limitation among US adults, 2015-2040. Arthritis Rheumatol 2016;68:1582-7. https://doi.org/10.1002/art.39692

3. Brady TJ, Murphy L, O'Colmain BJ, et al. A meta-analysis of health status, health behaviors, and healthcare utilization outcomes of the Chronic Disease Self-Management Program. Prev Chronic Dis 2013;10:120112. https://doi.org/10.5888/pcd10.120112

\section{World No Tobacco Day — May 31, 2017}

Each year, the global tobacco epidemic kills an estimated 6 million persons worldwide, including 600,000 who die from secondhand smoke exposure. If current trends continue, it is estimated that by 2030 tobacco use will result in approximately 8 million deaths worldwide annually; an estimated $80 \%$ of these preventable deaths will occur in low- and middle-income countries (1).

World No Tobacco Day, sponsored by the World Health Organization (WHO) and observed on May 31 each year, highlights the health risks associated with tobacco use and encourages effective actions to reduce tobacco consumption. This year, the theme for World No Tobacco Day is "Tobacco a Threat to Development" (2).

To support this theme, WHO is calling for activities that include international collaboration highlighting the links between the use of tobacco products, tobacco control, and sustainable development. In addition, WHO is calling for activities that demonstrate ways that individuals can contribute to bringing about a sustainable, tobacco-free world, either by committing to never start using tobacco products or by quitting such use (2).

\section{References}

1. Eriksen M, Mackay J, Schluger N, Gomeshtapeh F, Drope J. The tobacco atlas. 5th ed. Brighton, United Kingdom: American Cancer Society; 2015. http://www.tobaccoatlas.org

2. World Health Organization. World No Tobacco Day: 31 May 2017. Geneva, Switzerland: World Health Organization; 2017. http://www. who.int/campaigns/no-tobacco-day/2017/en/ 


\section{Erratum}

\section{Vol. 66, No. 14}

On page 392 in "QuickStats: Percentage Distribution of Gestational Age in Weeks for Infants Who Survived to Age 1 Year and Infants Who Died Before Age 1 Year - National Vital Statistics System, United States, 2014," the second and third sentences of the caption should have read as follows: "In $2014,66 \%$ of infants who survived to age 1 year were delivered at full term or later ( $\geq 39$ completed weeks) compared with $19 \%$ of infants who died before reaching age 1 year. Fifty-four percent of infants who died before age 1 year were delivered at $<32$ weeks gestation compared with only $1 \%$ of infants who survived to age 1 year." 